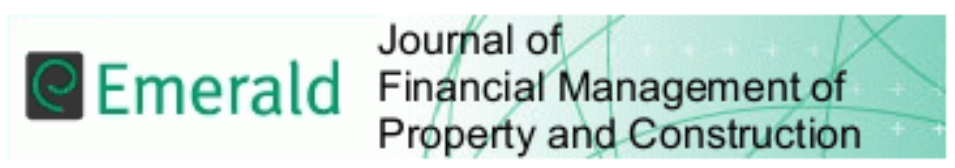

\title{
Real Options Analysis of Revenue Risk Sharing in Post- disaster Housing Reconstruction
}

\begin{tabular}{|r|l|}
\hline Journal: & Journal of Financial Management of Property and Construction \\
\hline Manuscript ID & JFMPC-02-2021-0018.R2 \\
\hline Manuscript Type: & Research Paper \\
\hline Keywords: & $\begin{array}{l}\text { Post-disaster housing reconstruction, Revenue risk, Public-Private } \\
\text { Partnerships, Real Option analysis, land readjustment }\end{array}$ \\
\hline
\end{tabular}

\section{SCHOLARONE \\ Manuscripts}




\title{
Real Options Analysis of Revenue Risk Sharing in Post-disaster Housing Reconstruction
}

\begin{abstract}
Purpose - Post-disaster housing reconstruction (PDHR) demands a considerable percentage of global property investment, yet the post-disaster environment presents intricate challenges to reconstruction financing for governments and at the same time, revenue uncertainty for private investors. The objective of this study was to develop a methodology for tackling land shortage and the financial challenges of PDHR in the aftermath of a disaster.

Design/methodology/approach - This study developed a methodology based on a combined minimum revenue guarantee (MRG) and maximum revenue cap (MRC) model using a well-established real options analysis (ROA) for revenue risk sharing in PDHR projects and LR for finance. The applicability of the purported model is demonstrated through an illustrative example.

Findings - The results show that flexibility in the options could increase the PDHR contractor's risk profile by increasing the expected value of the contractor investment and reducing the probability of investment loss. On the other side, a cap on the contractor revenue stream would allow the government to benefit from any excess in revenue and would counterbalance the value of the option.

Practical implications - The framework proposed in this study could serve as a practical risk-revenue sharing in PDHR projects. Governments and policymakers could use the findings to enable the successful delivery of PDHR projects and consequently bring the quality of life ${ }^{1}$ of affected people to pre-disaster conditions.

Originality/value - This study can be considered as a first attempt toward the use of the Australian barrier style options structure, and the trinomial lattice valuation model in PDHR projects, which incorporates LR, PPPs, governmental guarantees, and PDHR concepts in one ROA-based framework.
\end{abstract}

Keywords Post-disaster housing reconstruction; Land-readjustment; Public-private partnership; Revenue risk; Real options analysis

Paper type Research paper

${ }^{1}$ World Health Organization (WHO) defines quality of life as "an individual's perception of their position in life in the context of the culture and value systems in which they live and in relation to their goals, expectations, standards and concerns" 


\section{Introduction}

In recent decades the world has experienced an upsurge in the socio-economic consequences of natural disasters, with the number of victims totaling about 200 million in the last ten years. Residential areas are most vulnerable to natural disasters and represent the most significant share of losses from the impact of disasters within an economic area (Ahmed, 2011). The World Bank Post-Disaster Needs Assessment (PDNA) reported that, since 2000, residential real estate has sustained $40 \%$ to $90 \%$ of damage from natural disasters and has left 14 million people homeless each year (Suliman, 2017). In 2017 for example, disasters caused damage to or destroyed about 1.3 million housing units, causing more than $\$ 4.5$ billion in direct housing costs in the USA alone. In this situation, the major source of support for the recovery expenses of disaster-affected communities are international financial institutions, however, rising demands to finance post-disaster housing reconstruction (PDHR) despite the constant budget in recent decades accentuates the importance of the governments' post-disaster recovery assistance (Murao, 2020). On the broader, for governments seeking high-profile projects with an immediate impact on the population following a disaster, housing reconstruction is a smart move for two reasons. Firstly, infrastructure projects typically need more time and effort to finance and complete, and secondly, planning and implementing permanent housing reconstruction is vital for social cohesion, stemming losses to business establishments, and addressing disaster-caused public health problems (Arneson et al., 2020).

Post-disaster housing reconstruction (PDHR) can make a substantial contribution in providing a lasting haven for affected people by reducing the impact of natural disasters on communities at every level of intervention (Rotimi and Wilkinson, 2014). PDHR requires a sequence of decisions with longlasting impacts that must be made almost urgently in the aftermath of a disaster (Yi and Yang, 2014). Therefore, a lack of appropriate planning and implementation of recovery processes can bring more negative consequences than the disaster itself (Ismail et al., 2017). Chang et al. (2011) regarded PDHR as capital-intensive projects with characteristics that are different from traditional construction. Firstly, a considerable amount of costly and time-consuming activities (e.g., demolition of damaged structures) are essential for preparing affected areas for reconstruction. For example, after the Christchurch earthquake (New Zealand), around 1000 commercial properties and 10,000 to 15,000 residential properties were required to be demolished, generating more than 8 million tons of debris (Domingo and Luo, 2017). Secondly, post-disaster recovery priorities such as emergency health care, temporary housing, re-establishment of damaged urban infrastructures might result in an increase in recovery expenses to the point that financing a PDHR could become unachievable. Finally, after a disaster, reconstruction costs could experience significant growth due to increased demand for workforce and materials (Ahmadi Esfahani and Shahandashti, 2020).

On the other hand, adequacy and readiness of funding plans could further strengthen the 
confidence and certainty of decision-makers, residents, investors in post-disaster rebuilding (Liu et al., 2016). Land readjustment (LR) is significant to the rebuilding of cities after destructive natural disasters, especially in the face of land shortages or funding problems (Bai et al., 2020). LR implementation is relatively self-financing and could provide houses for those made homeless near their former neighbors. It seems that implementing LR as a large-scale project under public-private partnerships (PPPs) is one of the most innovative ways of financing infrastructure (Squires et al., 2016). The private sector could be responsible for a considerable number of functions related to the recovery activities and would be better to reap the benefits of a successful LR plan as a finance and land acquisition framework for PDHR. Although, Trangkanont and Charoenngam, (2014) have indicated that the PPP project procurement method in some cases failed to deliver low-cost housing in developing countries. The probability of the actual revenue dropping below the expected revenue could cause reluctance of private investors to participate in post-disaster PPPs (Shan et al., 2010). Apart from revenue uncertainty after project completion, disputes in the sharing of costs and benefits between parties are a possibility, when an LR plan is used (Turk and Korthals-Altes, 2011).

Government support in the form of minimum revenue guarantees (MRGs) can lessen revenue risk and stimulate private investments in PPP projects. Although MRGs aim to provide value to the project and attract investors, if left unmanaged, they can place an enormous financial burden on the public budget and leave the government responsible for all contingent liabilities and obligations over a short period. Scholars suggest that placing a limit on contractors' revenue, called an MRC (maximum revenue cap), can counterbalance the guaranteed value and allow the government to benefit from any excess in revenue. Almassi et al. (2013) suggest that an essential step in such a risk-revenue sharing mechanism is to establish a practical and accurate valuation approach for the guarantee, especially at the negotiation stage of PPP projects. This would allow both parties to analyze the cost-benefits of the support over the lifetime of the guarantee and benefit the government in the case of high revenues while limiting contractor exposure to revenue risk.

Real option analysis (ROA) is a powerful valuation approach that provides an integrated framework to evaluate investment opportunities under complex dynamic market uncertainties, such as PPP procurements. Given the aforementioned importance of decision-making after a destructive disaster, a reliable option valuation model can effectively enrich development decisions. Furthermore, the ROA can overcome shortcomings of discounted cash flow (DCF) methods to account for strategic flexibility (e.g. waiting and phasing) during the lifecycle of construction projects. A mounting number of studies have been leveraged to develop ROA models for governmental support valuation in PPP infrastructure construction (eg, Iyer and Sagheer, 2011; Jeong et al., 2016; Park et al., 2013; Sun and Zhang, 2015; Wang et al., 2018). However, some knowledge gaps justify a study of ROA valuation of governmental guarantees in PDHR projects is required. 1) limited research has focused on the effectiveness of government guarantees and ROA application in PDHR project decision-making. 2) The majority of ROA models found in the literature can be categorized as European or American styles with 
full coverage of the concession period with a single exercise right. 3) Apart from Tu et al.(2012), most researchers have not used ROA valuation for post-disaster LR projects in the form of PPPs. 4) PPPs in post-disaster management research have not been delved into deeply, particularly in a quantitative manner.

An Australian option is a financial derivative that provides the holder a right, not the obligation to exercise the option multiple times on prespecified dates during its lifespan, while the times that the option can be exercised can be fewer than the time steps. It means that a guaranteed coverage period can be divided into exercise periods and non-exercise periods (Almassi et al., 2013). The barrier style option makes it possible that the exercised right becomes activated upon the crossing of an option activator level. As concluded by Tserng et al., (2012) barrier style options have significant advantages for the construction industry, in their work they showed that putting an activator level can be used as a useful bargaining tool in the pre-construction phase for measuring contractor default using only timely stock information. These unique features of the Australian barrier style option make it flexible enough to cover a whole PDHR project from initial stages to the end while exercise right is limited to predefined price and the period where there is a revenue stream. In the highly uncertain context of PPP/PDHR projects actual future revenue of investors may be higher or lower than anticipated however there is no need to exercise the guarantee right over the whole lifecycle of the project. This suggests the use of the Australian barrier style option to model government revenue guarantee.

Consequently, it seems worthwhile to evaluate the effect of governmental guarantees in PDHR as the primary motivation for the current study. The main contribution and innovation envisaged are to address the current knowledge gap by applying a ROA to develop a framework for sharing revenue risk in PDHR projects which are delivered under PPP and LR for finance and tackling possible land-shortage problems considering the contractor's revenue. To accomplish the aim, the research objective of the paper is to (1) apply ROA for valuation of combined MRC and MRG options in PDHR projects, (2) show the applicability of LR and PPPs for financing PDHR projects, and (3) illustrate the applicability of Australian barrier style option for characterizing PDHR investment. The merit of the current study besides the application context is that the methodology then builds a trinomial lattice model of Australian barrier style options to calculate the value and determine the optimal timing for exercising the options.

The remainder of the study is structured as follows. Firstly, a review of PDHR, LR, and government guarantees in PPP projects is undertaken. Then an Australian barrier options-based methodology is presented for valuing governmental guarantees with a focus on LR for addressing land shortages and financial challenges in disaster-affected areas. Finally, the applicability of the proposed methodology is demonstrated through an illustrative example of housing reconstruction following the 2019 flood in Golestan province in Iran. 


\section{Previous works}

\subsection{ROA for governmental support valuation in PPP Infrastructure developments}

In PPPs arrangements, the private sectors undertake an important role, and governments have access to private capital, as well as to the technical capabilities that allow them to build, operate, maintain, and manage many types of infrastructure. To attract private sectors to partake in such investments, the governmental sector might guarantee a minimum level of profitability on every occasion the actual revenue fall below an expected minimum level. The main challenge that the government faces is the estimation of the budget committed to the project since its determination is a function of future uncertainty. Previously a growing number of studies have leveraged to develop ROA models for governmental support valuation in infrastructure construction. For example, to assess the value of governmental guarantees for highway construction projects subject to minimum traffic guarantee Brandao and Saraiva (2008) developed a model based on ROA to assess the value of governmental guarantees for highway construction projects subject to a minimum traffic guarantee (MTG). They concluded that using PPPs with guarantees and caps on total government outlays can be modelled efficiently using option valuing approaches and can be a means for attracting private investors to partake in risky public infrastructure projects. In similar research, Ashuri et al. (2012) used a real options pricing method called risk-neutral valuation with which to determine the exact value of the MRG for BOT toll road projects. The private sector can use this proposed model to make better entry decisions to BOT highway projects considering the level of support provided by the government. Also, Park et al. (2013) presented a ROA-based contract model to guarantee risk-sharing between the private and public sectors for privatized water and sewer systems. The proposed model can further organize contractual agreements that lead to a win-win situation for all contracting parties and even the public. Furthermore, Wang, Cui, and Liu (2018) established an optimal incentivize mechanism to guarantee project revenue and used the reciprocal preference theory to analyze the risk-sharing proportion that is most appropriate for the government. The results indicate that by setting a different guarantee strategy for different participants, the government can utilize reciprocal preference to incentivize investors to exert more effort during a partnership and avoid moral hazards. So also, Soltani and Firouzi, (2020) proposed a real options model for valuing flexibility in operation and maintenance contracts for water pipelines using reliability-based analysis. Zhang et al., (2021) introduced a type of option known as "swing option" to model a revenue risk allocation contract in PPP projects; which, can be used for hedging the underlying risk in two directions above and below expected values. In their work, an MRG and excess revenue sharing (ERS) are integrated. Ali et al. (2012); Park et al (2013) and Suttinon and Nasu (2010), provided other examples of ROA application for water and wastewater projects.

The significance of the valuation of government support mechanisms explains the growing attention given by researchers to ROA, and specifically to developing models and analytical methods 
to value offered guarantees. A review of previous works shows that apart from methods and techniques deployed, government guarantee mechanisms commonly fall into two broad categories of (1) Toll road projects (2) Water and wastewater projects. In contrary to PDHR where rapid response and early reconstruction play a pivotal role in restoring affected people's lives to normal conditions. In PDHR contract period is considerably shorter and the construction and operation phases are integrated. Nonetheless, toll road and water PPP projects typically have discrete phases of concession, including a relatively short period of construction, followed by a long phase of operation and maintenance, where the revenue is collected in terms of tariff on passing vehicles or consumed water. In most projects, the concession period is over several decades, at the end of the concession, the private sector transfers the ownership to the government. Despite sharing some central characteristics with PDHR projects in both finance method and implementation contexts, it seems to the authors that the study of ROA valuation of governmental guarantees in PDHR projects will be worthwhile.

\subsection{ROA for housing projects and land-readjustment practices}

Numerous studies have addressed decision-making flexibilities in housing practices by adopting ROA which shows the pertinency of this pricing technique for land development. Amongst them, Cunningham (2006) employed a rich data set of parcel characteristics and real property transactions for the Seattle region in the USA to examine two estimates of real options for land markets. Cunningham indicated that developers considered real options analysis for future buildings when deciding whether to invest. Clapp, Bardos, and Wong (2012) presented and validated an innovative, pragmatic approach for measuring the value of the options for redevelopment using a standard hedonic dataset.

Baldi (2013) proposed a conceptual methodology based on ROA pricing techniques for the construction of a new multi-purpose building. Yao and Pretorius (2014) developed and tested a long-term American-style real options pricing model for valuing development land under leasehold in ten cases in Hong Kong involving the purchase, holding, conversion, and development of land. Further, Mintah et al. (2018) used real options pricing to value staging options embedded in residential projects, with their results showing that real options can deliver superior results compared to the DCF method. The applicability of LR in land development practices is also highlighted in many published research (e.g., Byahut and Mittal 2017; Muñoz Gielen 2016; Turk and Korthals Altes 2011), however, there is no practical research on the applicability of ROA models to assist decision making in LR implemented housing construction projects, nor on PDHR housing projects.

\section{Background}

\subsection{LR potential for response to PDHR challenges}

The number of natural disasters quadrupled in the past two decades and the globe is currently facing 500 natural disasters annually (Ismail et al., 2017). This shows that with the global population increases, the displacements caused by natural disasters have made housing reconstruction projects 
more complicated and dynamic, requiring considerable financial resources. For example, earthquakes in 2010 and 2011, which struck the Canterbury region of New Zealand, left nearly 450 ha of residential and public land unsuitable for residential redevelopment. This led to a decrease in available low-cost rental homes, which was associated with increased housing prices and considerable financial pressure on public budgets (Potter et al., 2015). Taheri Tafti and Tomlinson, (2013) reported that public policies after a disaster could fail to address housing needs. Their Report showed that post-disaster permanent housing policies in Bhuj (India), Bam (Iran), and Banda Aceh (Indonesia) were unable to provide adequate housing, especially for non-landowners, even a decade after experiencing disasters, primarily because the rebuilt house units were unaffordable for low and middle-income residents. Another dimension to the issue is that much current construction legislation was not drafted to cope with postdisaster realities or to operate under prevailing conditions in the aftermath of a disaster, thus constraining housing provision

LR is a land management approach that changes the approach to the provision of land for housing, improves infrastructure and public facilities, and redefines public spaces within urban limits. Since, in this method, lands do not need to be expropriated or purchased, land acquisition costs can be reduced; at the same time, proceeds from the divestiture of public facilities can be used in part to cover project costs (Turk and Korthals Altes, 2011). In an LR scheme, the land is temporarily transferred to a contractor for reconstruction. Upon completion, a percentage of the property will be returned to owners, and the remainder will be appropriated to finance reconstruction, develop infrastructure, and build homes for those who find themselves homeless (Byahut \& Mittal 2017). The self-financing capacity of LR makes it well-suited for financially constrained regions. Moreover, LR experience in many parts of the world shows that settlers stay in the project area after the project completion, which can be seen as a solution for a probable social resistance and cultural challenges following a compulsory community displacement and its subsequent environmental impacts.

Generally, LR can be implemented voluntarily when the government agrees with owners on the terms of readjustment or compulsorily when a government imposes terms upon the owners (Muñoz Gielen, 2016). Various land pooling strategies have been discussed in the literature. Bai et al. (2020), Hong and Needham (2007), and Tu et al. (2012) can be consulted for more details, as this is beyond the scope of this research.

\subsection{PPPs for post-disaster management}

Governments around the world can use diverse methods for financing PDHR; however, the participation of private sectors in public projects such as post-disaster management is central to deliver better services to the affected community. One key characteristic of PPP delivery procurement is to make use of the financial resources and technical capabilities of private institutions to realize the construction, operation, and maintenance of public infrastructure, which, like PDHRs, are characterized as government obligations (Liu et al., 2014). 
Furthermore, PPPs that have become a more common choice for policymakers with which to implement indispensable public infrastructure projects are a pioneering institutional approach to leveraging non-public sector efficiencies for public service (Vahdatmanesh \& Firouzi 2018). In comparison with traditional delivery methods, PPPs are riskier and surrounded by uncertainty, such as revenue risk. PPP contracts use a highly leveraged and structured closed deal with inflexibility in the project's revenues, known as 'project finance'. To ascertain that the project will be commissioned with a pre-determined budget and time, creditors do in-depth due diligence before lending (Firouzi and Meshkani, 2021). Therefore, restructuring of PPP contracts often is impractical; therefore, deviations in external investment conditions such as revenue fluctuations could make PPP/PDHR projects financially unviable or even lead the project into failure (Firouzi \& Vahdatmanesh 2019).

To address equity or long-term investor's concerns about the estimated revenue in disaster-affected regions, host governments might offer supportive packages. Possible means of support include the minimum revenue guarantee (MRG), maximum expense limit (MEL) (Ashuri et al., 2012). Park et al. (2013) cited MRG as a popular form of government incentive in PPP projects. In MRG, direct support is designed to alleviate the revenue risk of the concession. With a MRG in place, if the revenue over a specific period falls under the pre-agreed guaranteed amount, the government will reimburse the difference (Vahdatmanesh and Firouzi, 2020).

As discussed earlier, guarantee options represent the potential risks to the government. Carbonara et al. (2014) concluded that, when a concessionaire is offered excessive guarantees, efficiency gains will not occur. Therefore, to counterbalance the value of a MRG and to prevent the contractor from benefitting excessively from guaranteed added value, MRC can be used to protect the public sector. A combination of MRG and MRC could adjust the project cash flow as well as guarantee an acceptable return while covering the debt and reducing excessive government liabilities. However, if not accurately enumerated, MRG and MRC options could unbalance the contract financially and make it prone to early termination. This will give rise to the need for a precise valuation of MRG and MRC in the negotiation stage.

\subsection{Traditional NPV analysis:}

DCF methods such as net present value (NPV) have been used by investors to evaluate BOT projects using deterministic variables. Equations (1) and (2) mathematically represent the typical form of NPV and WACC (weighted average cost of capital) that is used to discount future cash flows (Mirzadeh and Birgisson, 2016):

$\mathrm{NPV}=-I_{0}+\sum_{i=1}^{t} \frac{F C F_{i}}{(1+W A C C)^{i}}$

where $I_{0}$ is the initial investment and $F C F_{\mathrm{i}}$ is the future net cash flow at the time $i$ and:

$\mathrm{WACC}=\frac{E}{V} \times R_{e}+\frac{D}{V} \times R_{d} \times\left(1-T_{c}\right)$ 
where $R d$ is the total cost of debt, $E$ is the market value of total equity, $D$ is the market value of total debt, $V$ is the total market value of the combined debt and equity of the company, $T c$ is the income tax rate and $R e$ is the total cost of equity and is estimated using the capital asset pricing model (CAPM) as: $R_{e}=r_{f}+\beta \times \mathrm{MRP}$ where $r_{f}$ is the risk-free interest rate, $\beta$ is the levered beta that measures the sensitivity of expected asset return to expected market return, and MRP is the market risk premium. In the current research, WACC has been used to discount the future revenue of each square meter of housing in the PDHR project.

The shortcomings of DCF methods such as NPV are well discussed in the literature (Kim et al., 2013; Mirzadeh and Birgisson, 2016). The NPV method assumes that the future cash inflows and outflows are static. However, the PDHR contractor's cash outflows of the project are consist of numerous cost components (e.g., material, labour, equipment) which in disaster-affected economies where are naturally surrounded by significant uncertainties might be subject to price fluctuations. Similarly, the cash inflows of the concessionaire that occur upon completion of each phase of the project are dependent on the projected revenue, which itself is subjected to high uncertainty in a post-disaster environment where socioeconomic status (e.g., Low rate of employment, Low local government revenue, high level of lost household income, etc.) of the community is affected in many ways (Rouhanizadeh et al., 2020). For example, the 2010 earthquake and subsequent tsunami in Chile caused widespread destruction. Two socioeconomic challenges to housing reconstruction were inadequate financial support for the reconstruction of low-income housing and the high costs of procurement of land for residents of regions that were categorized as unsafe for redevelopment due to the danger caused by tsunamis. Ashuri et al. (2012) concluded that there is a lack of a standard systematic approach in the conventional NPV to account for such financial risks. Thus, if the NPV method is deployed as the basis of decision-making for a PPP/PDHR investment, the financial viability of the project and the solvency of the contractor could be insufficient and, could cause the failure of the project.

As discussed in the literature revenue, to overcome the shortcomings of the NPV approach for characterizing revenue uncertainties in infrastructure investments, numerous researchers proposed and developed ROA-based frameworks. This study also intended to apply ROA to PDHR valuation for two reasons, first, static investment evaluation approaches such as NPV are inadequate to properly evaluate PDHR projects since they do not explicitly capture and treat uncertainty about future price movements, Second, in uncertain environments aftermath a disaster socio-economic changes may gradually reveal; therefore, using ROA-based risk-sharing frameworks provide practitioners with managerial flexibilities to alter their operating strategies when needed.

\subsection{Real options analysis for post-disaster housing reconstruction}

\subsubsection{Governmental guarantees theory}


In real options the values of real asset uncertainty are reasonably reflected through the diffusion process, as shown in Eq. (4), where it is assumed that the stock price follows an uncertain diffusion with a lognormal distribution (geometric Brownian motion) as follows:

$\frac{d S}{S}=\mu d t+\sigma d z$

where $S$ is the stock price, $\mu$ is the instantaneous rate of return, $\sigma$ is the volatility of underlying asset, and $d z$ is a random increment for a standard Weiner process (Luenberger, 1998).

A governmental MRG in a PDHR project which can provide downside protection for contractor revenue is an arrangement in which one party, i.e., the government, commits to compensating the contractor for a revenue shortfall $(C-X)$ relative to period $\Delta t$, which is the difference between minimum guaranteed revenue $C$ and the revenue accumulated at $\Delta t, X$. An MRG is similar to possessing the right to sell the services at a specific price. Hence, it offers the same rights as a put option.

Conversely, should the PDHR project revenue surpass the initial pre-specified levels $(X-C)$, the government should demand repayment of the excess revenue. This represents another form of real option known as MRC which is a type of call option with annual maturity, that can be exercised by the government. For the current study, it has been supposed that the contractor minimum revenue has been agreed upon by the public and private sector and is set as the exercise price. In the proposed methodology, the guarantees are modeled as barrier options. The activator levels of the MRG and MRC options $\left(A C_{M R G}\right.$ and $\left.A C_{M R C}\right)$, defined as a percentage of revenue, must be agreed upon in negotiations between the contractor and government.

It has been assumed that the contractor and the public sector have the option to exercise. By matching the option value of the MRG, which is the potential gain from the perspective of the contractor to the potential loss (option value of the MRC), the risks associated with the PDHR project can be distributed between the contracting parties (Park et al., 2013). The total value of the options can be determined as follows:

Total real option value $=\mid$ MRG option value - MRC option value $\mid$

The primary purpose of offering embedded real options in construction projects is to make the project attractive; therefore, from the contractor's perspective, the condition in Eq. (6) must be satisfied (Carbonara et al., 2014) as:

$\sum_{i=1}^{t} \frac{F C F_{t}}{(1+W A C C)^{i}}+$ Total real option value $-\sum_{i=1}^{t} \frac{I_{t}}{(1+W A C C)^{i}} \geq 0$

where $I_{t}$, and $F C F_{t}$ are the investment and future net cash flow at the time, respectively. In the current research, both the ROA and NPV approaches have been used to determine the value of a post-disaster housing project with MRG and MRC options.

\subsubsection{Australian options guarantee framework}

An option provides its holder with a right without obligation to make profitable decisions regarding the underlying asset. The decision can be exercised after the revelation of information within a previously 
Although American and European options are more commonplace guarantee frameworks, in a study by Chiara et al., (2007) it was shown that using an Australian options structure allows both private and public sectors to fairly share the revenue risks of infrastructure projects. In this regard, the authors believe that Australian options can also be beneficial to projects like PDHRs with a period (e.g., land preparing stage) without any revenue stream where there is no need to option exercise. Moreover, contrary to single exercise options, the multiple-exercise nature of the Australian option allows the whole guarantee period to be covered with a single option framework. As confirmed by This feature, might lead to fewer financial commitment and administrative costs compared to American and European counterparts with single-time exercise. If an option is agreed to be activated after the price becomes higher or lower than a pre-agreed level rather than the exercise price, it is called a barrier style option (Almassi et al., 2013). The barrier style option provides parties with a more flexible exercise right and bargaining range which possibly adds more managerial flexibility to the project. Furthermore, it can limit the guarantee's availability to be exercised in the early stages of a PDHR. In the Australian barrier style option, which is the focus of this study, one level above and/or below the exercise price (option activator level) can be set by parties to activate their rights when the barrier is hit at an exercise date that precedes the expiration date (Tserng et al., 2012). A typical Australian option guarantee framework is presented in Fig. 1.

\section{[Figure.1]}

\subsection{Trinomial lattice model for Australian barrier options}

Real option modelling can be generally done by utilising analytical closed-forms, discrete-time lattice models (e.g., binomial and trinomial), and simulation techniques (e.g., least-square Monte Carlo). Lattice models have many advantages and for three main reasons are widely used to characterize uncertainties around infostructure investments (1) lattices are straight-forward numerical methods (2) they are easily applicable to most types of real options even with numerous variable parameters (3) In infrastructure investments, strategic managerial decisions are taken at a discrete moment, rather than continuously (Luenberger, 1998). 
As an extension to Cox et al., (1979) work who developed the binomial lattice valuation technique for the first time, Boyle (1986) developed a trinomial lattice. Binomial and trinomial lattice models are conceptually equivalent since both methods are equivalent to the explicit finite difference method for option pricing. One key aspect that makes trinomial lattice models superior to their binomial counterparts is that in addition to up movement $\left(\mathrm{p}_{\mathrm{u}}\right)$, and down movement $\left(\mathrm{p}_{\mathrm{d}}\right)$ probabilities, trinomial lattice model incorporate the third probability $\left(\mathrm{p}_{\mathrm{c}}\right)$ which incorporates a zero change in value over a period. As a result, the trinomial lattice model produces more accurate and realistic results. Based on this analysis, this study utilizes the discrete-time trinomial lattice model. Fig. 2 shows a generic trinomial tree.

\section{[Figure.2]}

The trinomial tree sizes can be calculated using Eqs. (7) to (11). Up and down jump sizes are calculated as:

$$
\begin{aligned}
& \mathrm{u}=\mathrm{e}^{\sigma \sqrt{2 \Delta t}} \\
& \mathrm{~d}=\mathrm{e}^{-\sigma \sqrt{2 \Delta t}}
\end{aligned}
$$

For the time-discrete random motion of asset value $C^{i}$ over time, $t=t_{i}$ can jump at time $t_{i}+\Delta t$ to $u C$. Probability $p_{u}$, will decrease to $d C^{i}$ at probability $p_{d}$, or remain constant with probability $\left(1-\mathrm{p}_{\mathrm{u}}-\mathrm{p}_{\mathrm{d}}\right.$ ). The probabilities can be obtained as:

$$
\begin{aligned}
& p_{u}=\left(\frac{e^{\frac{r_{r} \Delta t}{2}}-e^{-\sigma \sqrt{\frac{\Delta t}{2}}}}{e^{\sqrt{\frac{\Delta t}{2}}}-e^{-\sigma \sqrt{\frac{\Delta}{2}}}}\right) \\
& p_{d}=\left(\frac{e^{\sigma \sqrt{\frac{\Delta t}{2}}}-e^{\frac{r_{r} \Delta t}{2}}}{e^{\sigma \frac{\sqrt{\frac{t}{2}}}{2}}-e^{-\sigma \sqrt{\frac{\Delta}{2}}}}\right) \\
& p_{c}=1-p_{u}-p_{d}
\end{aligned}
$$

where $r_{f}$ is the risk-free rate of interest and $\sigma$ is the volatility.

The option value can be obtained using another tree. Backward recursion from the final node to node 0 of the tree for the value of the option at each exercise date can be calculated using Eqs. (12) to (16). The payoff to the MRG (put option) and MRC (call option) options, when exercised at the expiration date $\left(\mathrm{T}_{0}\right)$, can be obtained as follows (Ritchken, 1995):

$$
\begin{aligned}
& V_{\text {MRC. }} C_{i}^{T_{0}}= \begin{cases}\operatorname{Max}\left[0, C_{i}^{T_{0}}-X\right], & \text { If } C_{i}^{T_{0}} \geq A C_{M R C .} . \\
0 & \text { If } C_{i}^{T_{0}}<A C_{M R C .}\end{cases} \\
& V_{\text {MRG. }} C_{i}^{T_{0}}= \begin{cases}\operatorname{Max}\left[0, X-C_{i}^{T_{0}}\right], & \text { If } C_{i}^{T_{0}} \leq A C_{\text {MRG. }} . \\
0 & \text { If } C_{i}^{T_{0}}>A C_{\text {MRG. }}\end{cases}
\end{aligned}
$$




\section{Proposed methodology}

The flowchart of the proposed methodology for evaluating the MRG and MRC options in a PPP/PDHR project is summarized in Fig. 3. The steps are:

1. Specify project valuation inputs, as described in section 3.1. This information will be used to calculate the deterministic and probabilistic NPV of the project using the Monte Carlo simulation.

2. Specify the LR plan specifications, the percentage of land that will be pooled for allocation to infrastructure development, original landowners, residents whose homes have been destroyed, and commercial units.

3. Calculate the probability of NPV $<0$ using both Monte Carlo simulation and deterministic approaches, as shown in Eqs. (1) to (3) to characterize the contractor risk profile.

4. Based on the project delivery plan, divide the operational phase of the LR plan into N discrete annual time steps. The time steps in which the options can be exercised, reimbursement strategy, and option activator level (P) for both public and private sectors must be determined in this step.

5. Construct a risk-neutral trinomial lattice $C_{i}^{t_{0}}$ where $i=0: t_{0}$ and $t_{0}=0: T_{0}$ using Eqs. (7) to (11) to characterize revenue uncertainty over $\mathrm{N}$ discrete time steps.

6. Create a valuation lattice $V_{M R G} C_{i} c_{i}$ where $i=0$ and $t_{0}, t_{0}=0: T_{0}$ using backward recursion (Eqs. (12), (14), and (16)) starting from time step $T_{0}$ until all nodes of the lattice are covered.

7. Create valuation lattice $V_{M R C} C_{C_{i}}^{t_{0}}$ where $i=0: t_{0}$ and $t_{0}=0: T_{0}$ using backward recursion (Eqs. (13), (15), and (16)) from $T_{0}$ until all nodes of the second lattice are covered.

8. Perform sensitivity analysis to determine the effect of changes in volatility, risk-free rate of interest, and guaranteed activator level. This can help parties decide when to use the options.

9. Complete the decision-making process and determine whether Eq. (6) has been established.

A worked example is presented next to demonstrate the applicability of the methodology.

[Figure.3] 


\subsection{Data collection}

The proposed methodology model requires three data sets as inputs for step 1 of the methodology. Set 1 is the PPP/PDHR project lifecycle cash flow, consisting of the required capital, annual construction costs per square meter of housing (e.g., material, labor, equipment), administrative costs, and annual corporate tax of the host country over the concession lifetime. Set 2 is the contractor's capital structure. The contractor capital costs can be defined using WACC. This rate can be used as a discount rate for investment valuation. Set 3 is the data required for the ROA from the trinomial lattice model for capturing uncertainty regarding the future revenue of the project. This dataset includes the timestep, risk-free interest rate, which can be calculated using the average rate of return for host country treasury bonds and the annual volatility of revenue.

Kim et al. (2013) reported that, for PPP investment projects, the forecasted annual fluctuation of the gross domestic product of the project region could be used as a proxy for annual volatility $(\sigma)$. The minimum revenue can be used as the exercise price agreed upon at the negotiation stage. Option activator levels (option barriers) also can be agreed upon at the negotiation stage. Section 4 describes this backward calculation algorithm using a simple notional worked example.

\section{Illustrative example}

\subsection{Project profile}

In March 2019, massive floods hit several parts of Iran, resulting in severe damage to more than 86,000 houses (with a built-up area of approximately $86,000,000 \mathrm{~m}^{2}$ ). In Golestan province in the northeast of the country, the subsequent landslides and inundation led to more severe damage to residential areas and infrastructures, leaving many areas uninhabitable and thousands homeless. Fig. 4 illustrates satellite-detected surface water in lands that appear to be flooded in the western part of Golestan province as of 29 March 2019.

Due to budget constraints and to accelerate reconstruction, the local government in Golestan province outsourced the entire post-earthquake reconstruction process through an LR scheme using the PPP delivery method to build a 15,000-unit project. According to the LR plan, $50 \%+10 \%$ of each land parcel will be appropriated for former and new residents, $10 \%$ of the land will be used for new infrastructures, and $20 \%$ of the land will be allocated to the contractor to cover construction costs and profits. The remaining $10 \%$ will be used by the government to build commercial units to cover unforeseen expenditures. This information will be used in step 2 of the methodology.

Two concession phases were planned. In phase one, in year one, damaged houses will be demolished, and the area will be prepared for construction work; in years two through four, 5,000 units will be completed by the end of each year. Phase two of the project starts from year three, with the construction of commercial properties. Because there is revenue risk from uncertainty in the value of commercial properties, to enhance the marketability of the project, the local government will offer MRG as an option to be exercised by the concessionaire at the end of years two, three, and four. 
[Figure.4]

The $A C_{M R G}$, and $A C_{M R C}$ for the options in this study are $5 \%$ higher than the exercise price for the MRC, and 5\% lower than the exercise price for the MRG option. These values have been chosen arbitrarily; however, to show the effect of change in the option activator value, sensitivity analysis has been conducted. Economic parameters as was done in a similar construction project in the region using 10-year historical data from 2008 to 2018 required for NPV calculation of the project are presented in Table 2.

\section{[Table.2]}

\subsection{Results and discussion}

\subsubsection{Approach A: PDHR project valuation using conventional NPV}

This approach is described in step 3 of the proposed methodology (Fig. 3). Initially, it is assumed that there are no real options in the project; therefore, there is no managerial flexibility. The conventional NPV method is used to evaluate contractor investment valuation. Except in year one of the contract, that there is $\$ 52,000,000$ in expenditure for preparing the land for construction. Operational cost for year two is $\$ 119,047,619$, with a $3 \%$ administrative cost, the revenue is $\$ 142,857,143$ with an annual most likely growth rate of $17 \%$, which is obtained using triangular distribution based on historical data of similar projects.

The deterministic NPV of the contractor in the PDHR project is calculated at $\$ 8,287,878$. Although this positive value indicates that the contractor should invest in the PDHR project, the probability distribution of the concessionaire NPV using Monte Carlo simulation in Fig. 5 indicates that the expected NPV of the project is $\$ 8,535,408$, with a standard deviation (SD) of $\$ 9,403,831$. This indicates that there is a nearly $36 \%$ chance (SD of 0.027 ) that the project NPV will become negative.

\section{[Figure.5]}

\subsubsection{Approach B: PDHR project using ROA}

To illustrate the applicability of the methodology, the ROA was applied to determine the contractor and the local government risk profile using the MRG and MRC options. The spot price of the underlying assets was equal to the estimated revenue from the sale of commercial units after subtraction of the construction costs for the commercial and residential units in the year before the commencement date of the contract. In comparison with the international market, the construction costs in Iran are relatively low because of government subsidies on the price of energy, low labor, and material costs. Using data from similar projects in Golestan province, the current net revenue with a $12 \%$ profit margin for a contractor in Iran is estimated to be $\$ 47.6$ per $\mathrm{m}^{2}$ of built area for a total profit of approximately $\$ 71,400,000$ (as of October 2019) for delivery of 15,000 houses with an average built area of $100 \mathrm{~m}^{2}$ on three delivery dates. Because of the multiple-exercise feature of Australian options, $\$ 23,805,000$ $(\$ 71,400,000 / 3)$ was used as the node 0 value of the underlying assets in the trinomial lattice. For steps 
4 and 5, Eqs. (7) to (11) can be used to calculate future revenue movements. Table 3 lists the trinomial tree valuation parameters realized from Eqs. 9 to 11 .

\section{[Table.3]}

In year two, the revenue may increase with an upward movement factor of $u=1.28$ at $P_{u}=0.40$, remain constant with a probability of $0.46\left(1-P_{u}-P_{d}\right)$, or decrease with a downward movement factor $(d=0.8)$ and a probability of 0.14 . Table 4 indicates that revenue from the first exercise date will be $\$ 14,717,879$ to $\$ 38,502,696$. Using the trinomial lattice results in Table 4 at each exercise date will produce an array of possible revenue values for the PDHR Golestan project. This suggests that, if the PPP/PDHR project does not follow a revenue risk management policy, the revenue at each delivery date could fluctuate considerably. In year four, for example, the revenue could fall between $\$ 9,099,600$ and $\$ 62,275,050$. This is a $684 \%$ potential revenue difference, which would result in significant uncertainty in the revenue of the project.

\section{[Table.4]}

\subsection{3. $M R G$ and $M R C$ valuation}

ROA was conducted using backward recursion in the trinomial lattice model. The variables required for ROA are summarized in Table 5. Also, the data provided in Tables 6 and 7 show the risk-neutral trinomial lattice as decision trees using Eqs. (16) and (17). These lattices evaluate real options embedded in the MRG and MRC criteria for private and public entities, respectively.

[Table.5]

For MRG (step 6), when a fall in annual revenue causes the actual rate of return of the PPP contract to drop below the option activator value, then the contractor can exercise the option, and the government must compensate for the difference by transferring the ownership of the commercial built area to the contractor. To avoid complexity in calculations, the average annual estimated revenue of the PPP/PDHR project of $\$ 23,805,000$ ( $\$ 47.6$ revenue from $1 \mathrm{~m}^{2}$ of housing) is the exercise price each year. Moreover, it was assumed that the option activator level was agreed to be 5\% higher than the exercise price for the MRC option and 5\% lower than the exercise price for the MRG option. These percentages represent the amount of risk that the contractor and government should be prepared to accept. For example, starting at the expiration date where the payoff at each node equals $\max \left[0, C_{i}^{4}\right.$ $-(0.95 \times \$ 23,805,000)]$ and moving backward in nodes $V_{M R G 2}^{2}$ and $V_{M R G 4}^{2}$, the payoff of the option would be 0 . In nodes $V_{M R G_{0}^{2}}^{2}$ and $V_{M R G 1}^{2}$, the payoff would yield $\$ 9,087,121$ and $\$ 5,087,118$, respectively. In these nodes, the contractor will have the right to ask the government to pay compensation equal to the option payoff.

[Table.6]

The MRG option value in the PPP/PDHR project in Golestan province can be obtained by moving backward on the lattice. The value of node $0\left(t_{0}=0\right)$ makes the value of MRG equal to $\$ 1,906,986$ (see column 1 in Table 6.). This amount represents the present net value of MRG of about 23\% of the 
total capital expenditure of the project; hence, the effect of the MRG option on the project value cannot be ignored. In other words, $t_{0}=0$ (beginning of PDHR project guarantee) is the option premium which the local government offered to the contractor using the MRG option in the PPP concession agreement. This puts a base on the projected revenue and reduces the chance of negative NPV, providing the contractor with managerial flexibility of exercising the revenue guarantee.

From the governmental perspective, putting a cap on the revenue guarantee transfers the revenue risk to the public sector. In the proposed methodology, it is assumed that the difference between the revenue cap and the actual revenue will be reimbursed by granting ownership of the commercial built areas which is indicated in the LR plan to the contractor. Because the contractor might receive an excess in benefits the from MRG option, to counterbalance the MRG value and fairly share the risk and revenue of the project, the contractor and the government will agree on repayment of revenues that are higher than the option activator level of 5\% above the contractor's minimum expected revenue.

[Table.7]

In step 7, the decision tree and the MRC option value can be obtained as in the MRG lattice using the backward recursion. The option value $\left(t_{0}=0\right)$ is $\$ 4,209,899$, which is $50 \%$ of the net value of the project. Table 7 shows that, for example, in year three, the option payoff for nodes $V_{M R C_{3}^{3}}: V_{M R C_{6}}^{3}$ will be $\$ 2,441,097$ to $\$ 26,992,115$. In the rest of the nodes, the MRC option payoff will be 0 , which means that the revenue of the project produces an actual rate of return that is higher than the option barrier (activator) level. Therefore, the government can exercise its right to ask the contractor to repay the excess amount equal to the MRC option payoff. All the nodes for which the MRC and MRG options can be exercised are shown in Tables 6 and 7.

The sensitivity analysis (step 8) results in Figs. 6 to 8 show the effect of the activator level, volatility, and risk-free change on the option prices and the option activator level on the value of MRG and MRC, respectively. The MRG and MRC values increased as the volatility increased, whereas the value of MRC increased as the risk-free rate increased, which had the opposite effect on the value of MRG. An MRG value that falls below $-30 \%$ of the exercise price as the option barrier level (option activator) is 0 . This level for the MRC is greater than $10 \%$ of the exercise price at each time step. The proposed PDHR valuation approach can be employed when both MRG and MRC options are considered simultaneously.

\section{[Figure.6] \\ [Figure.7] \\ [Figure.8]}

Tables 6 and 7 show the difference in the MRG and MRC option values is $\$ 2,302,913(\$ 4,209,899$ $\$ 1,906,986)$. Although the MRC value is greater than for the MRG, step 9 stipulates that the sum of the NPV and options value will be $\$ 5,984,874$. This value means that the contractor should invest in the project with real options. 


\subsection{Results Summary}

Fig. 9 summarizes the results of the proposed methodology. It can be seen that, while uncertainty about the PPP/PDHR projected revenue increased as the end of the project approached. This rate of increase over 48 months represents significant uncertainty for the project's revenue. The revenue from the delivery of the final 5,000 houses at the end of year three could reach $\$ 48,966,900$, which is $205 \%$ of the value at the beginning of the Golestan project and embodies $\$ 25,161,900$ in extra profits to the contractor. At the same time, it puts an excessive financial burden on the public budget. At this delivery point, revenue could fall to $\$ 11,572,675$, which represents a $51.4 \%$ loss to the contractor compared to the profit expected before the construction phase began. The use of MRG and MRC options in the project's revenue guarantee plan would limit the revenue risk during the project lifecycle by preserving a minimum revenue level for the contractor and sharing the excess profits with the government when revenue goes higher than or drops below the guaranteed exercise level.

[Figure.9]

Assuming that the guarantee contains activator levels for both the MRC and MRG as barrier options, the proposed methodology will provide both parties with more flexibility regarding the option exercise right. This will reduce the value of the options by decreasing the probability of exercising them. However, when negotiating the option activator levels, sensitivity analysis is central to the decision-making process because it examines the effect of change in the activator levels on the total guaranteed value. For example, in this case study, the activator level should be from $-2 \%$ to $+2 \%$ of the exercise price (Fig. 8); otherwise, the value of one or both MRG and MRC options may fall to zero.

\section{Conclusion and implications}

Post-disaster reconstruction finance and land development have always been amongst significant challenges to governments' attempts to respond to the negative consequences of disasters. PPPs are popular delivery methods but riskier than traditional projects. Therefore, many governments offer revenue guarantees to attract private investors. A methodology based on real options analysis (ROA) was developed in this paper for the valuation of government guarantees in PPP/PDHR projects, which uses LR to overcome funding and land shortage problems. The nine-step methodology considers the uncertainty of future revenues in the valuation of PPP/PDHR projects and characterizes both government and contractor's economic risk under future revenue uncertainty. Shortcomings in the DCF valuation method, ROA concepts, and the various real option styles are introduced, and the rationale behind the selection of the Australian barrier style option has been presented. An algorithm has been developed to value the MRG and MRC using the trinomial lattice model, and an example has been provided to demonstrate its applicability in PPP/PDHR projects.

The numerical results from the Golestan province case study reveal that the use of the MRG and MRC in a PDHR project can safeguard the contractor against revenue risk as well as benefit 


\section{References}

Ahmadi Esfahani, N. and Shahandashti, M. (2020), "Post-hazard labor wage fluctuations: a comparative empirical analysis among different sub-sectors of the U.S. construction sector”, Journal of Financial Management of Property and Construction, Vol. 25 No. 3, pp. 313-330.

Ahmed, I. (2011), “An overview of post-disaster permanent housing reconstruction in developing countries", International Journal of Disaster Resilience in the Built Environment, Vol. 2 No. 2 , pp. 148-164.

Almassi, A., Mccabe, B., Thompson, M. and Yu, X. (2013), "Real Options - Based Approach for Valuation of Government Guarantees in Public - Private Partnerships”, Journal of Infrastructure Systems, Vol. 19 No. 2, pp. 196-204.

Arneson, E., Javernick-Will, A., Hallowell, M. and Corotis, R. (2020), "Predicting Postdisaster Residential Housing Reconstruction Based on Market Resources", Natural Hazards Review, American Society of Civil Engineers (ASCE), Vol. 21 No. 1, p. 04019010.

Ashuri, B., Kashani, H. and Lu, J. (2010), "Financial Valuation of Risk and Revenue Sharing Options in Build-Operate-Transfer (BOT) Highway Projects", Engineering Project ..., No. January 2010, available at: http://academiceventplanner.com/EPOC2010/Papers/EPOC_2010_AshuriKashaniLu.pdf.

Ashuri, B., Kashani, H., Molenaar, K.R., Lee, S. and Lu, J. (2012), "Risk-Neutral Pricing Approach for Evaluating BOT Highway Projects with Government Minimum Revenue Guarantee Options", Journal of Construction Engineering and Management, Vol. 138 No. 4, pp. 545-557. 
Bai, Y., Zhou, W., Guan, Y., Li, X., Huang, B., Lei, F., Yang, H., et al. (2020), "Evolution of policy concerning the readjustment of inefficient urban land use in China based on a content analysis method", Sustainability (Switzerland), MDPI AG, Vol. 12 No. 3, available at:https://doi.org/10.3390/su12030797.

Baldi, F. (2013), "Valuing a greenfield real estate property development project: a real options approach”, Journal of European Real Estate Research, Vol. 6 No. 2, pp. 186-217.

Boyle, P.P. (1986), “Option Valuation Using a Three-Jump Process”, International Options Journal, Vol. 3, pp. 5-12.

Byahut, S. and Mittal, J. (2017), "Using land readjustment in rebuilding the earthquake-damaged City of Bhuj, India", Journal of Urban Planning and Development, Vol. 143 No. 1, pp. 1-11.

Carbonara, N., Costantino, N. and Pellegrino, R. (2014), "Revenue guarantee in public-private partnerships: a fair risk allocation model", Construction Management and Economics, Vol. 32 No. 4, pp. 403-415.

Çete, M. (2010), “Turkish land readjustment: Good practice in urban development”, Journal of Urban Planning and Development, Vol. 136 No. 4, pp. 373-380.

Chang, Y., Wilkinson, S., Brunsdon, D., Seville, E. and Potangaroa, R. (2011), “An integrated approach: Managing resources for post-disaster reconstruction”, Disasters, Blackwell Publishing Ltd, Vol. 35 No. 4, pp. 739-765.

Chiara, N., Garvin, M.J. and Vecer, J. (2007), "Valuing Simple Multiple-Exercise Real Options in Infrastructure Projects", Journal of Infrastructure Systems, Vol. 13 No. 2, pp. 97-104.

Clapp, J.M., Bardos, K.S. and Wong, S.K. (2012), "Empirical estimation of the option premium for residential redevelopment", Regional Science and Urban Economics, Elsevier B.V., Vol. 42 No. $1-2$, pp. 240-256.

Cox, J.C., Ross, S.A. and Rubinstein, M. (1979a), “Option pricing: A simplified approach”, Journal of Financial Economics, Vol. 7 No. 3, pp. 229-263.

Cox, J.C., Ross, S.A. and Rubinstein, M. (1979b), “Option pricing: A simplified approach”, Journal of Financial and Quantitative Analysis, Vol. 7, pp. 229-263.

Cunningham, C.R. (2006), "House price uncertainty, timing of development, and vacant land prices: Evidence for real options in Seattle", Journal of Urban Economics, Vol. 59 No. 1, pp. 1-31.

Domingo, N. and Luo, H. (2017), "Canterbury earthquake construction and demolition waste management: issues and improvement suggestions", International Journal of Disaster Risk Reduction, Elsevier Ltd, Vol. 22, pp. 130-138.

Firouzi, A. and Meshkani, A. (2021), "Risk-based optimization of the debt service schedule in renewable energy project finance”, Utilities Policy, Elsevier Ltd, Vol. 70, p. 101197.

Firouzi, A. and Vahdatmanesh, M. (2019), “Applicability of Financial Derivatives for Hedging Material Price Risk in Highway Construction”, Journal of Construction Engineering and Management, Vol. 145 No. 5, p. 04019023. 
Freeman, P.K. (2004), “Allocation of post-disaster reconstruction financing to housing”, Building Research and Information.

Garvin, M.J. (2010), "Enabling Development of the Transportation Public-Private Partnership Market in the United States", Journal of Construction Engineering and Management, Vol. 136 No. 4 , pp. 402-411.

Holland, H. (2018), "Confronting the Land-Shortage Problem in Detroit: A Proposal for Land Readjustment", Wayne Law Review, Vol. 64, available at: https://heinonline.org/HOL/Page?handle=hein.journals/waynlr64\&id=865\&div=\&collection= (accessed 13 April 2020).

Hong, Y.-H. and Needham, B. (2007), Analyzing Land Readjustment: Economics, Law, and Collective Action, Lincoln Institute of Land Policy.

Huang, Y. and Chou, S. (2006), "Valuation of the minimum revenue guarantee and the option to abandon in BOT infrastructure projects", Construction Management and Economics, Vol. 24 No. 4, pp. 379-389.

Ismail, F.Z., Halog, A. and Smith, C. (2017), "How sustainable is disaster resilience?: An overview of sustainable construction approach in post-disaster housing reconstruction", International Journal of Disaster Resilience in the Built Environment, Vol. 8 No. 5, pp. 555-572.

Iyer, K.C. and Sagheer, M. (2010), "Hierarchical Structuring of PPP Risks Using Interpretative Structural Modeling”, Journal of Construction Engineering and Management, Vol. 136 No. 2 , pp. 151-159.

Iyer, K.C. and Sagheer, M. (2011), “A real options based traffic risk mitigation model for buildoperate-transfer highway projects in India", Construction Management and Economics, Vol. 29 No. 8, pp. $771-779$.

Jeong, J., Ji, C., Hong, T. and Park, H.S. (2016), "Model for Evaluating the Financial Viability of the BOT Project for Highway Service Areas in South Korea", Journal of Management in Engineering, Vol. 32 No. 2, p. 04015036.

Kim, D.Y., Ashuri, B. and Han, S.H. (2013), "Financial Valuation of Investments in International Construction Markets: Real-Options Approach for Market-Entry Decisions", Journal of Management in Engineering, Vol. 29 No. 4, pp. 355-368.

Liu, J., Yu, X. and Cheah, C.Y.J. (2014), "Evaluation of restrictive competition in PPP projects using real option approach", International Journal of Project Management, Elsevier B.V., Vol. 32 No. 3, pp. 473-481.

Liu, M., Scheepbouwer, E. and Giovinazzi, S. (2016), "Critical success factors for post-disaster infrastructure recovery : learning from the Canterbury ( NZ ) earthquake recovery”, Disaster Prevention and Management: An International Journal.

Luenberger, D. (1998), Investment Science, Oxford University Press., New York.

Mintah, K., Higgins, D., Callanan, J. and Wakefield, R. (2018), “Staging option application to 
residential development: real options approach", International Journal of Housing Markets and Analysis, Emerald Group Publishing Ltd., Vol. 11 No. 1, pp. 101-116.

Mirzadeh, I. and Birgisson, B. (2016), "Evaluation of Highway Projects under Government Support Mechanisms Based on an Option-Pricing Framework", Journal of Construction Engineering and Management, Vol. 142 No. 4, p. 04015094.

Muñoz Gielen, D. (2016), "Proposal of Land Readjustment for the Netherlands: An analysis of its effectiveness from an international perspective", Cities, Elsevier B.V., Vol. 53, pp. 78-86.

Murao, O. (2020), "Recovery curves for housing reconstruction from the 2011 Great East Japan Earthquake and comparison with other post-disaster recovery processes", International Journal of Disaster Risk Reduction, Elsevier Ltd, Vol. 45, p. 101467.

Park, T., Kim, B. and Kim, H. (2013), "Real option approach to sharing privatization risk in underground infrastructures", Journal of Construction Engineering and Management, Vol. 139 No. 6, pp. 685-693.

Potter, S.H., Becker, J.S., Johnston, D.M. and Rossiter, K.P. (2015), “An overview of the impacts of the 2010-2011 Canterbury earthquakes", International Journal of Disaster Risk Reduction, Elsevier Ltd, Vol. 14, pp. 6-14.

Ritchken, P. (1995), “On Pricing Barrier Options”, The Journal of Derivatives, Pageant Media US, Vol. 3 No. 2, pp. 19-28.

Rotimi, J.O.B. and Wilkinson, S. (2014), "Improving environmental management legislation to facilitate post-disaster reconstruction", International Journal of Disaster Resilience in the Built Environment, Vol. 5 No. 1, pp. 23-37.

Rouhanizadeh, B., Kermanshachi, S. and Nipa, T.J. (2020), "Exploratory analysis of barriers to effective post-disaster recovery", International Journal of Disaster Risk Reduction, Vol. 50, p. 101735 .

Shan, L., Garvin, M.J. and Kumar, R. (2010), "Collar options to manage revenue risks in real toll public-private partnership transportation projects", Construction Management and Economics, Vol. 28 No. 10, pp. 1057-1069.

Soltani, M. and Firouzi, A. (2020), "Real Option Valuation of Flexibility in Operation and Maintenance Contracts of Water Pipelines Based on Reliability Analysis", Journal of Infrastructure Systems, Vol. 26 No. 1, p. 04019031.

Squires, G., Hutchison, N., Adair, A., Berry, J., McGreal, S. and Organ, S. (2016), "Innovative real estate development finance - evidence from Europe", Journal of Financial Management of Property and Construction, Emerald Group Publishing Ltd., Vol. 21 No. 1, pp. 54-72.

Suliman, A. (2017), "Disasters make 14 million people homeless each year: U.N. - Reuters", Reuters, available at: https://www.reuters.com/article/us-un-disaster-displacement/disasters-make-14million-people-homeless-each-year-u-n-idUSKBN1CH35D (accessed 19 June 2020).

Sun, Y. and Zhang, L. (2015), "Balancing public and private stakeholder interests in BOT 
concessions: Minimum revenue guarantee and royalty scheme applied to a water treatment project in china", Journal of Construction Engineering and Management, Vol. 141 No. 2, pp. 18.

Taheri Tafti, M. and Tomlinson, R. (2013), "The role of post-disaster public policy responses in housing recovery of tenants", Habitat International, Elsevier Ltd, Vol. 40, pp. 218-224.

Trangkanont, S. and Charoenngam, C. (2014), "Critical failure factors of public-private partnership low-cost housing program in Thailand", Engineering, Construction and Architectural Management, Emerald Group Publishing Ltd., Vol. 21 No. 4, pp. 421-443.

Tserng, H.P., Liao, H.-H.H., Jaselskis, E.J., Tsai, L.K. and Chen, P.-C.C. (2012), “Predicting Construction Contractor Default with Barrier Option Model", Journal of Construction Engineering and Management, Vol. 138 No. 5, pp. 621-630.

Tu, H.-N., Wang, L.-H. and Lin, C.-H. (2012), "The application of real options model on evaluating land readjustment project”, Journal of Statistics and Management Systems, Informa UK Limited, Vol. 15 No. 1, pp. 49-59.

Turk, S.S. and Korthals Altes, W.K. (2011), "Potential Application of Land Readjustment Method in Urban Renewal: Analysis for Turkey", available at:https://doi.org/10.1061/(ASCE)UP.

Vahdatmanesh, M. and Firouzi, A. (2018), "Price Risk Management in BOT Railroad Construction Projects Using Financial Derivatives", Journal of Financial Management of Property and Construction, Vol. 23 No. 3, pp. 349-362.

Vahdatmanesh, M. and Firouzi, A. (2020), "Construction material supply risk management using Asian option contracts: the case of a pipeline project", Engineering, Construction and Architectural Management, Vol. 27 No. 10, pp. 3395-3414.

Wang, Y., Cui, P. and Liu, J. (2018), “Analysis of the risk-sharing ratio in PPP projects based on government minimum revenue guarantees", International Journal of Project Management, Pergamon, Vol. 36 No. 6, pp. 899-909.

Wibowo, A. and Kochendoerfer, B. (2011), "Selecting BOT/PPP Infrastructure Projects for Government Guarantee Portfolio under Conditions of Budget and Risk in the Indonesian Context", Journal of Construction Engineering and Management, Vol. 137 No. 7, pp. 512-522. World Health Organization. (2012), "WHOQOL - Measuring Quality of Life| The World Health Organization", available at: https://www.who.int/toolkits/whoqol (accessed 24 August 2021). Yao, H. and Pretorius, F. (2014), "Demand Uncertainty, Development Timing and Leasehold Land Valuation: Empirical Testing of Real Options in Residential Real Estate Development", Real Estate Economics, Blackwell Publishing Ltd, Vol. 42 No. 4, pp. 829-868.

Yi, H. and Yang, J. (2014), "Research trends of post disaster reconstruction: The past and the future", Habitat International, Elsevier Ltd.

Zhang, S., Li, J., Li, Y. and Zhang, X. (2021), "Revenue Risk Allocation Mechanism in PublicPrivate Partnership Projects: Swing Option Approach”, Journal of Construction Engineering 
and Management, American Society of Civil Engineers (ASCE), Vol. 147 No. 1, p. 04020153. 
When the option barrier is reached, it can be redeemed in $M \leq N$

Fig.1 Australian option guarantee framework

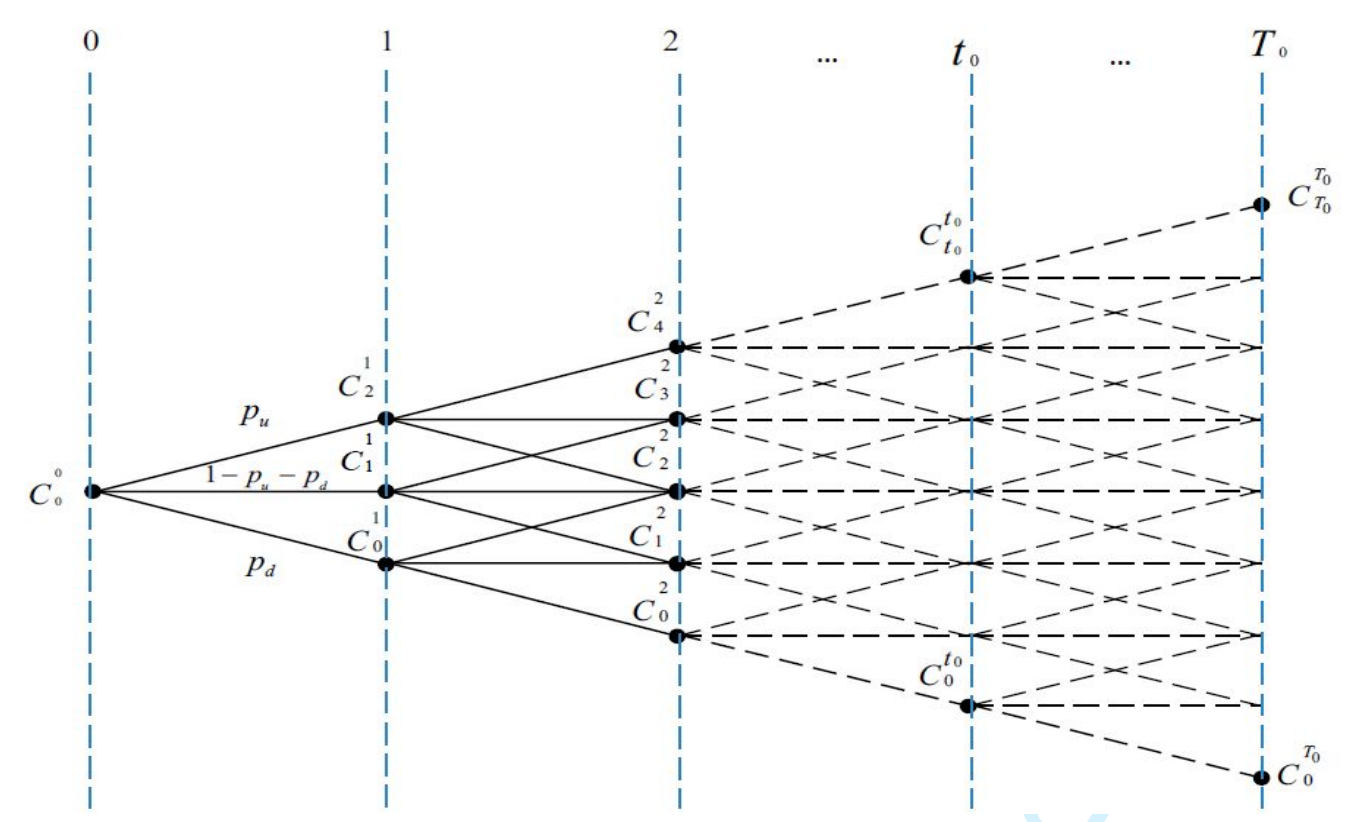

Fig. 2. Typical trinomial tree characterizing revenue uncertainty. 
Step 1.

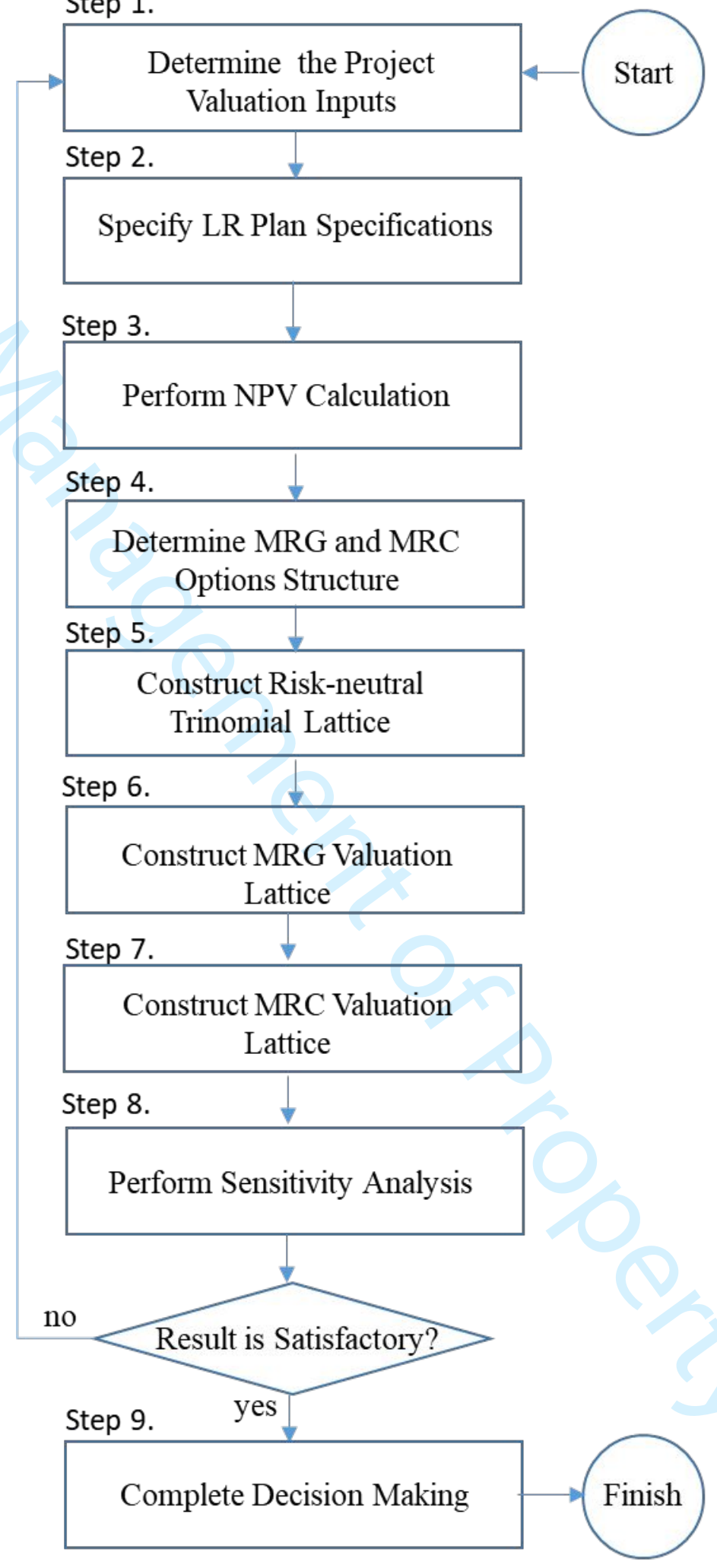

Fig. 3. ROA-based proposed methodology. 


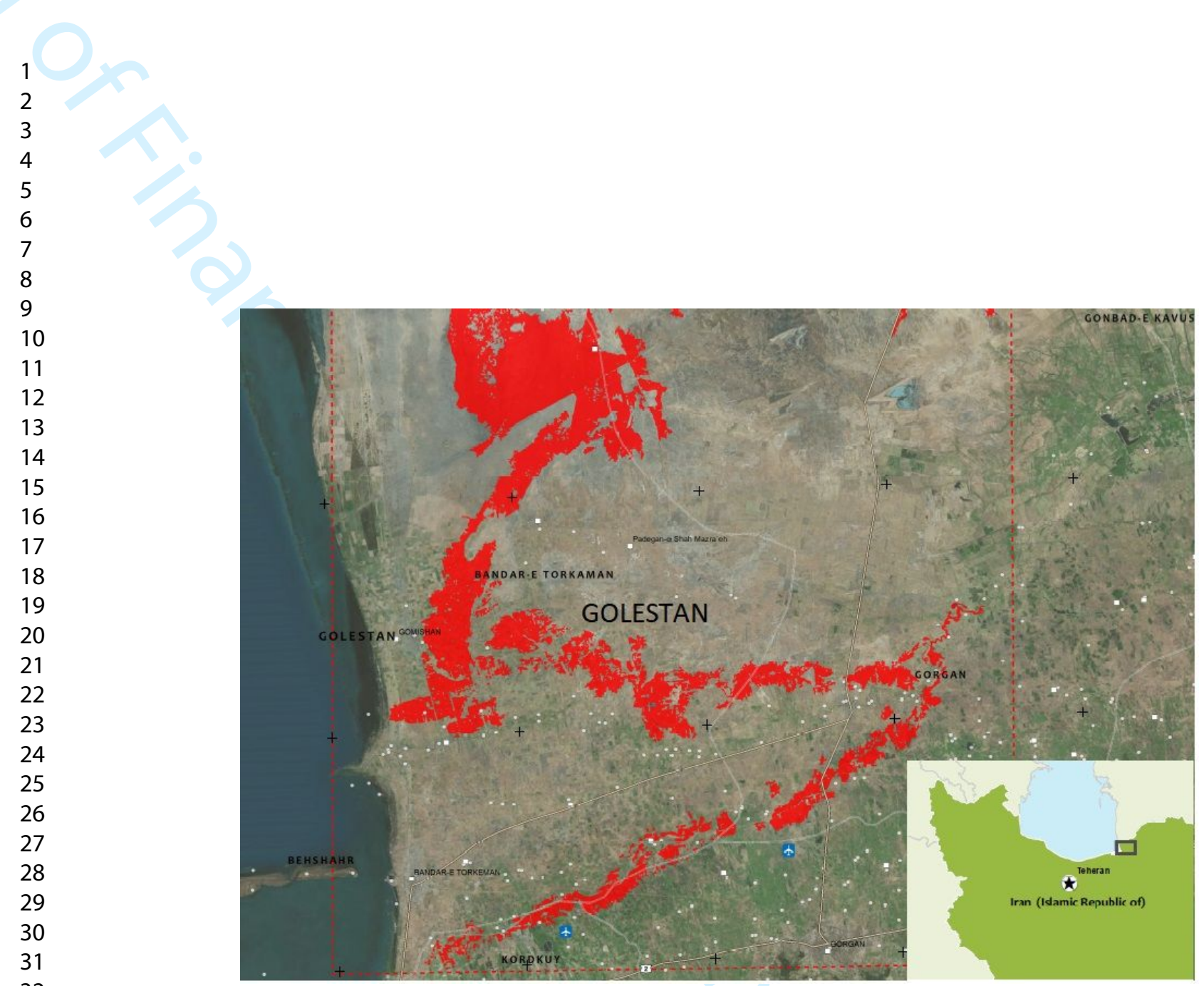

Fig. 4. Satellite detected water extent (shown in red color) as of 29 March 2019 over Golestan province.

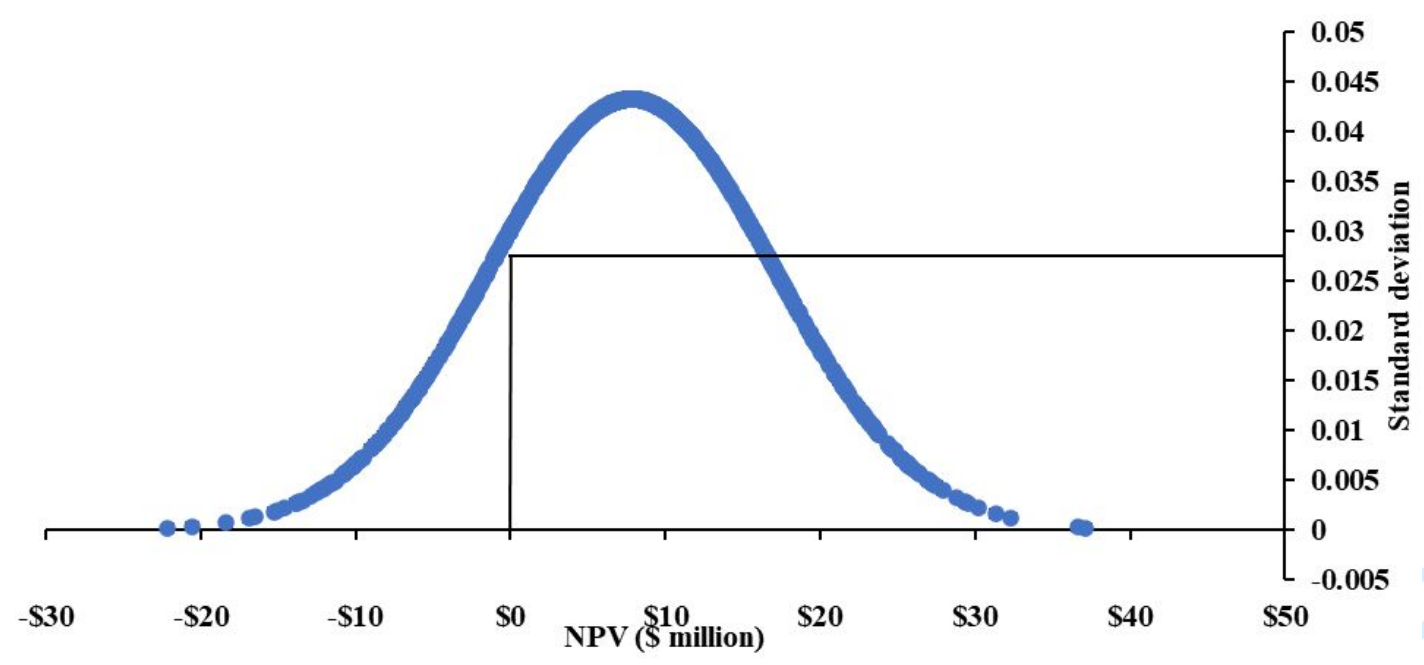

Fig. 5. Contractor financial risk profile of investment in the Golestan project. 


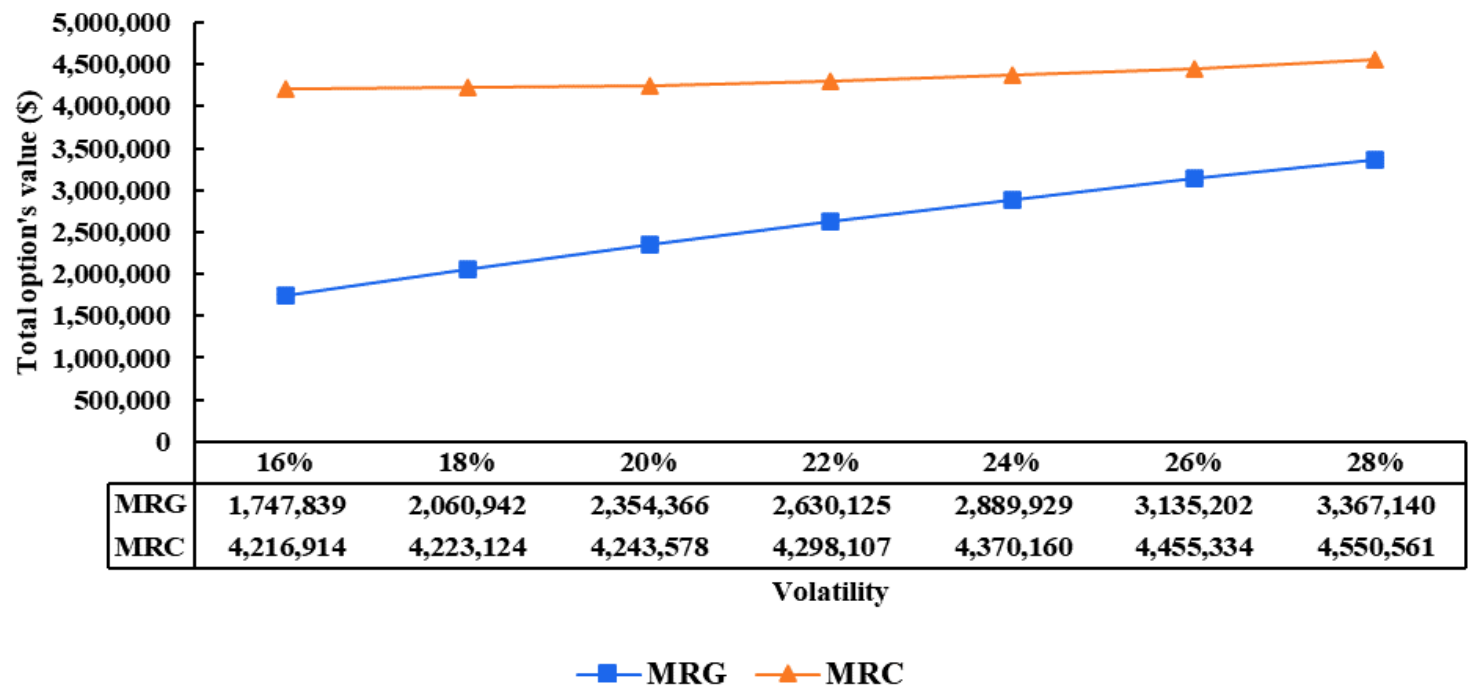

Fig. 6. Change in volatility on the total value of MRG and MRC options.

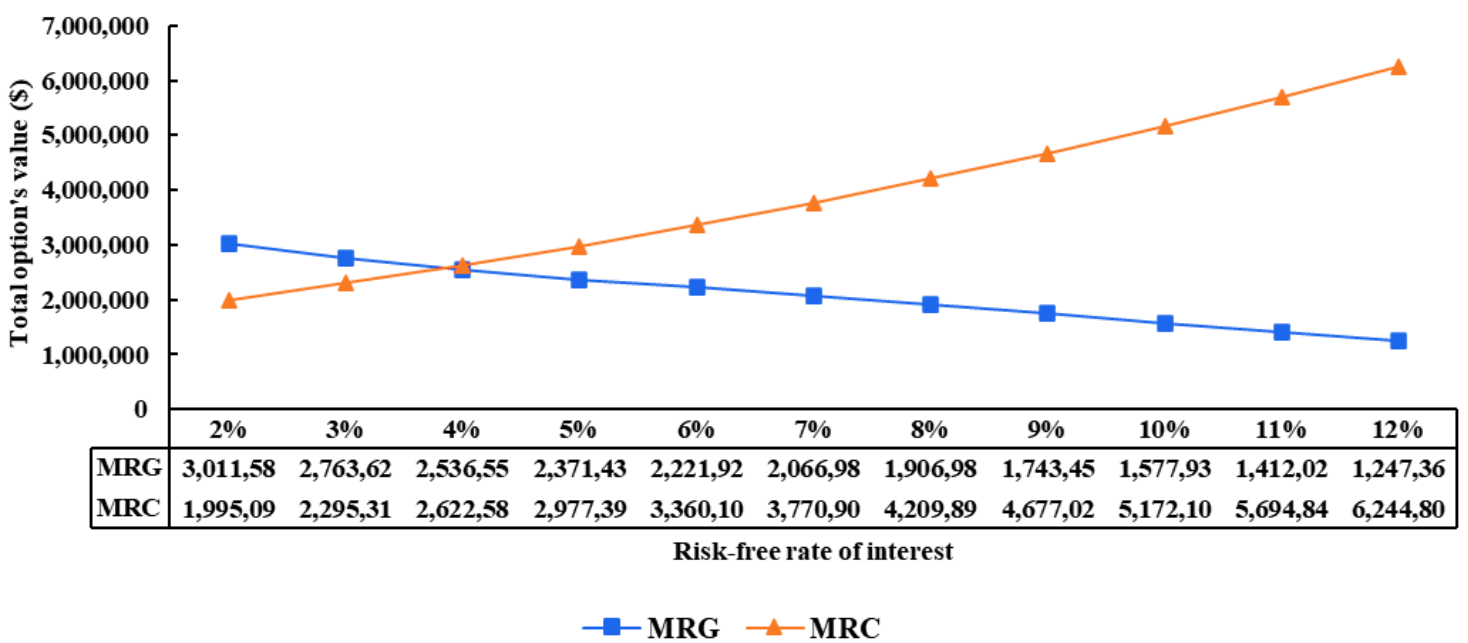

Fig. 7. Change in risk-free rate on total value of $M R G$ and $M R C$ options. 


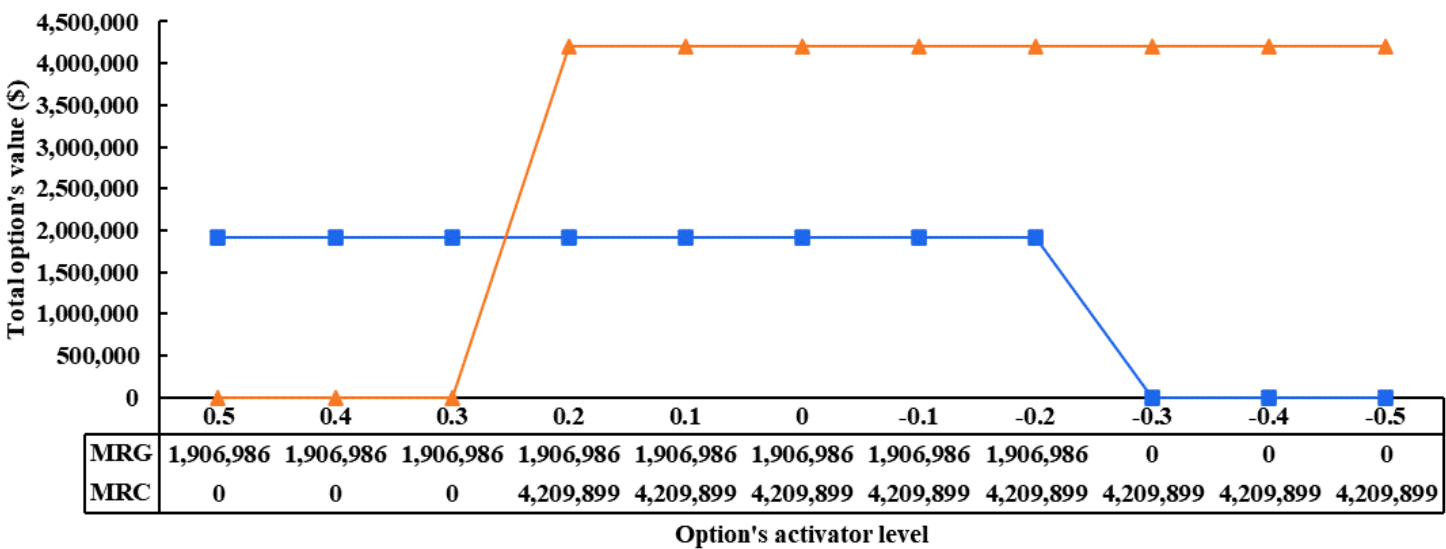

$$
\rightarrow-\text { MRG } \rightarrow \text { MRC }
$$

Fig. 8. Change in guarantee activator level on the total value of MRG and MRC options.

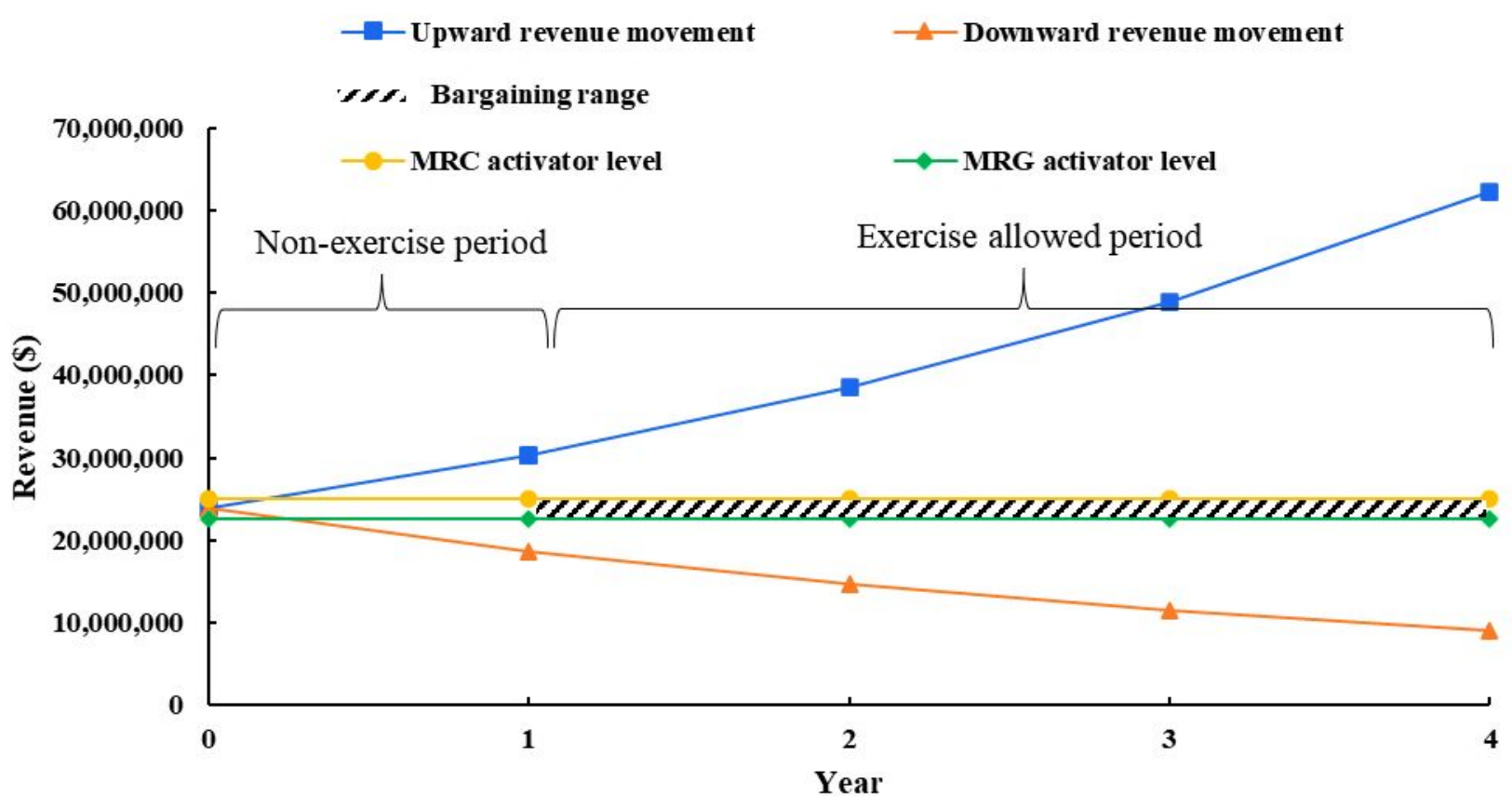

Fig. 9. Proposed methodology results in the case study. 
Table 1. American, European, Asian, and Australian options

\begin{tabular}{ll}
\hline Type of option & Characteristics \\
\hline American option & A single-exercise option that can be exercised once anytime during its life. \\
European option & A single-exercise option that can be exercised once, only at the its \\
expiration date. & A single-exercise option whose payoff depends on the average price of \\
Asian option & the underlying asset over a pre-determined period as a substitute of price at \\
Australian option & predetermined $N(M \leq N)$ dates until expiration date.
\end{tabular}

Table 2. Economic Parameters for NPV calculation

\begin{tabular}{|c|c|c|c|c|}
\hline Parameter description & Symbol & Unit & value & Calculation \\
\hline Weighted average cost of capital & WACC & $\%$ & 18.38 & Eqs. (1) to (3) \\
\hline Risk-free rate & $r_{f}$ & $\%$ & 8 & $\begin{array}{c}\text { Iranian long-term bond } \\
\text { interest }\end{array}$ \\
\hline Total capital cost of project & $T_{C}$ & $\$$ & $453,714,286$ & Project data \\
\hline Cost of equity & - & $\%$ & 15 & Similar project \\
\hline Corporate tax & - & $\%$ & 20 & Similar project \\
\hline Annual revenue growth rate & - & $\%$ & 17 & Similar project \\
\hline Annual project revenue & - & $\$$ & $47.6 / \mathrm{m}^{2}$ & Project data \\
\hline
\end{tabular}


Table 3. Calculated parameters for trinomial lattice valuation

\begin{tabular}{lccc}
\hline Parameter description & Symbol & Unit & Value \\
\hline Up movement factor & $u$ & - & 1.271 \\
Middle movement factor & $m$ & - & 1 \\
Down movement factor & $d$ & - & 0.786 \\
Up movement factor & $p_{u}$ & - & 0.408 \\
Middle movement probability & $p_{m}$ & - & 0.461 \\
Down movement factor & $p_{d}$ & - & 0.13 \\
\hline
\end{tabular}

Table 4. Trinomial lattice to model revenue uncertainty

\begin{tabular}{ccccc}
\hline $\boldsymbol{t}_{\mathbf{0}}=\mathbf{0}$ & $\boldsymbol{t}_{\mathbf{0}}=\mathbf{1}$ & $\boldsymbol{t}_{\mathbf{0}}=\mathbf{2}$ & $\boldsymbol{t}_{\mathbf{0}}=\mathbf{3}$ & $\boldsymbol{t}_{\mathbf{0}}=\mathbf{4}$ \\
\hline$\$ 23,805,000$ & $\$ 30,274,687$ & $\$ 38,502,696$ & $\$ 48,966,900$ & $\$ 62,275,050$ \\
& $\$ 23,805,000$ & $\$ 30,274,687$ & $\$ 38,502,696$ & $\$ 48,966,900$ \\
$\$ 18,717,882$ & $\$ 23,805,000$ & $\$ 30,274,687$ & $\$ 38,502,696$ \\
& $\$ 18,717,882$ & $\$ 23,805,000$ & $\$ 30,274,687$ \\
& $\$ 14,717,879$ & $\$ 18,717,882$ & $\$ 23,805,000$ \\
& & $\$ 14,717,879$ & $\$ 18,717,882$ \\
& & $\$ 11,572,675$ & $\$ 14,717,879$ \\
& & & $\$ 11,572,675$
\end{tabular}


Table 5. Input variables for real option analysis

\begin{tabular}{lccc}
\hline Parameter description & Symbol & Unit & Value \\
\hline Value of underlying asset in the first year & $C_{0}$ & $\$$ & $23,805,000$ \\
Duration of the guarantee period & $T_{0}$ & year & 4 \\
Exercise price & $X_{C}$ & $\$$ & $23,805,000$ \\
MRG option barrier level & $A C_{M R G}$ & $\$$ & $22,614,750$ \\
MRC option barrier level & $A C_{M R C}$ & $\$$ & $24,995,250$ \\
The risk-free rate of interest & $r_{f}$ & - & $8 \%$ \\
Annual volatility of underlying assets & $\sigma$ & - & $17 \%$ \\
\hline
\end{tabular}

Table 6. Values of MRG option and exercise decision at each node.

\begin{tabular}{|c|c|c|c|c|c|c|c|}
\hline \multirow[t]{2}{*}{$t_{0}=0$} & \multirow[t]{2}{*}{$t_{0}=1$} & \multicolumn{2}{|c|}{$t_{0}=2$} & \multicolumn{2}{|c|}{$t_{0}=3$} & \multicolumn{2}{|c|}{$t_{0}=4$} \\
\hline & & & & & & wait & $\$ 0$ \\
\hline & & & & & & wait & $\$ 0$ \\
\hline & & & & wait & $\$ 0$ & wait & $\$ 0$ \\
\hline & & & & wait & $\$ 0$ & wait & $\$ 0$ \\
\hline & & wait & $\$ 0$ & wait & $\$ 0$ & wait & $\$ 0$ \\
\hline & & wait & $\$ 0$ & wait & $\$ 0$ & exercise & $\$ 5,087,118$ \\
\hline & $\$ 0$ & wait & $\$ 0$ & exercise & $\$ 5,087,118$ & exercise & $\$ 9,087,121$ \\
\hline & $\$ 0$ & exercise & $\$ 5,087,118$ & exercise & $\$ 9,087,121$ & exercise & $\$ 12,232,325$ \\
\hline$\$ 1,906,986$ & $\$ 4,479,445$ & exercise & $\$ 9,087,121$ & exercise & $\$ 12,232,325$ & exercise & $\$ 14,705,400$ \\
\hline
\end{tabular}


Table 7. Values of MRC option and exercise decision at each node

\begin{tabular}{|c|c|c|c|c|c|c|c|}
\hline \multirow{2}{*}{$\begin{array}{c}\boldsymbol{t}_{\mathbf{0}}=\mathbf{0} \\
\$ 4,209,899\end{array}$} & \multirow{2}{*}{$\begin{array}{c}\boldsymbol{t}_{\mathbf{0}}=\mathbf{1} \\
\$ 11,157,579\end{array}$} & \multicolumn{2}{|c|}{$t_{0}=2$} & \multicolumn{2}{|c|}{$t_{0}=3$} & \multicolumn{2}{|c|}{$t_{0}=4$} \\
\hline & & exercise & $\$ 18,217,413$ & exercise & $\$ 26,992,115$ & exercise & $\$ 38,470,050$ \\
\hline & $\$ 0$ & exercise & $\$ 10,062,761$ & exercise & $\$ 16,527,911$ & exercise & $\$ 25,161,900$ \\
\hline & $\$ 0$ & wait & $\$ 0$ & exercise & $\$ 8,299,902$ & exercise & $\$ 14,697,696$ \\
\hline & & wait & $\$ 0$ & exercise & $\$ 2,441,097$ & exercise & $\$ 6,469,687$ \\
\hline & & wait & $\$ 0$ & wait & $\$ 0$ & wait & $\$ 0$ \\
\hline & & & & wait & $\$ 0$ & wait & $\$ 0$ \\
\hline & & & & wait & $\$ 0$ & wait & $\$ 0$ \\
\hline & & & & & & wait & $\$ 0$ \\
\hline & & & & & & wait & $\$ 0$ \\
\hline
\end{tabular}




\section{The Journal of Financial Management of Property and Construction Author(s') Response to Reviewers Form}

Manuscript ID: (JFMPC-02-2021-0018.R1)

The quality of the paper is improved and all my $\quad$ Many thanks for this encouraging general comment. comments are addressed.

I would like to wish the author(s) good luck in their future researches.

1. Originality: Does the paper contain new and significant information adequate to justify publication?

The presented paper has the merit to get published in this reputable journal.

Relationship to Literature: (a) Does the paper demonstrate an adequate understanding of the relevant literature in the field and cite an appropriate range of literature sources? (b) Is any significant work ignored?

The literature review is fair and covers most of the extant work in this field.

Methodology: (a) Is the paper's argument built on an appropriate base of theory, concepts, or other ideas? (b) Has the research or equivalent intellectual work on which the paper is based been well designed? (c) Are the methods employed appropriate?

Yes, the proposed model is well designed and established on basic real options concept exist in the literature.

Results: (a) Are results presented clearly and analysed appropriately? (b) Do the conclusions adequately tie together the other elements of the paper?:

Yes, both presentation of results and conclusion are coherent and well presented.

Implications for research, practice and/or society: (a) Does the paper identify clearly any implications for research, practice and/or society? (b) If applicable, does the paper bridge the gap between theory and practice? (c) If applicable, does the paper demonstrate how the research may be used in practice (economic or commercial impact); in teaching; to influence public policy; in future research? (d) What is the impact upon society (influencing public attitudes, affecting quality of life)? (e) Are any stated implications consistent with the findings and conclusions of the paper?

Yes, a case example is used to show the implications of the proposed model.

Quality of Communication: (a) Does the paper clearly $\quad$ The authors are thankful for this comment. express its case, measured against the technical language of the field and the expected knowledge of

Many thanks for this good comment.

The authors are grateful for this comment.

This good comment is appreciated.

Again many thanks for this comment.

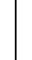

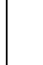


the journal's readership? (b) Has attention been paid to the clarity of expression and readability, such as sentence structure, jargon use, acronyms, etc.:

Yes, the quality of communication is acceptable.

\section{Referee 2}

I hope the author(s) find my suggestions helpful in $\quad$ The authors are very thankful for the reviewer's improving the readability of the paper. I wish them good luck as they work on this interesting line of research.

- Originality: Does the paper contain new and significant information adequate to justify publication?:

Yes

Relationship to Literature: (a) Does the paper demonstrate an adequate understanding of the relevant literature in the field and cite an appropriate range of literature sources? (b) Is any significant work ignored?:

Yes. However, the author(s) might want to consider adding the results of the studies which they mention in a sentence or two. This will tie up the literature well to the theory and their paper.

For example: In page 5 - the authors mention a number of papers and what the research was. If they can mention the results too, it will be more holistic.

See Page 6 line 30 - 32 - the authors have presented the paper and the results clearly.

They can attempt to do so for the papers in page 5 lines $8-45$ or tie up the papers to the results on page 5 lines 46-60 and page 6 lines 1-9.

Methodology: (a) Is the paper's argument built on an appropriate base of theory, concepts, or other ideas? (b) Has the research or equivalent intellectual work on which the paper is based been well designed? (c) Are the methods employed appropriate?: Yes Results: (a) Are results presented clearly and analysed appropriately? (b) Do the conclusions adequately tie together the other elements of the paper?: Yes

Implications for research, practice and/or society: (a) Does the paper identify clearly any implications for research, practice and/or society? (b) If applicable, does the paper bridge the gap between theory and practice? (c) If applicable, does the paper demonstrate how the research may be used in practice (economic or commercial impact); in teaching; to influence public policy; in future research? (d) What is the impact upon society (influencing public attitudes, affecting quality of life)? (e) Are any stated implications consistent with the findings and conclusions of the paper?:

Yes

Quality of Communication: (a) Does the paper clearly express its case, measured against the technical language of the field and the expected knowledge of the journal's readership? (b) Has attention been paid to the clarity of expression and readability, such as sentence structure, jargon use, acronyms, etc.:

Many thanks for these comments which enhance the quality of the literature review. To address this comment in section 2.1, the results of some of the most relevant reviewed works are presented.

Many thanks for this comment.

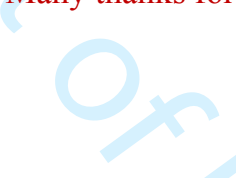

The authors are thankful to the reviewer for this good comment.

Many thanks for this positive comment.
Many thanks for recommending this paper for publication in JFMPC.

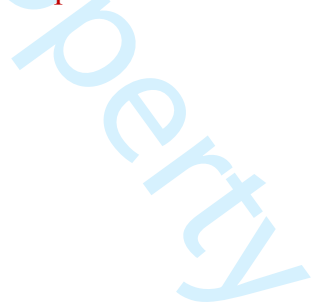


a) Yes

b) No.

The paper should go through a round of editing and housekeeping.

Example: Page 1, line 36 - explain what is meant by "quality of life"

Page 2, line 25-26, Page 3, line 1: replace "on the other hand" (on the other hand usually follows on the one hand)

Page 4, line 6: Replace ignored with another suitable word

Page 4, line 21-22, line 31-32: Rewrite clearly.

Page 9, lines 30-38: Sentence is too long. Break up sentence.

Check for capital letters / commas / etc (page 2, line 53)
Authors response to point (a):

Many thanks for this comment.

Authors' response to point (b):

The authors are very grateful for these constructive comments which enhance the quality of communication of the paper. To address these issues the following steps are now taken:

1. In the footnote of page 1, a definition of "quality of life by World Health Organization (WHO) is presented."

2. "On the other hand" is now replaced with "On the broader".

3." have ignored" is now replaced with "have not used".

4. The sentence is now rewritten as" As concluded by Tserng et al., (2012) barrier style options have significant advantages for the construction industry, in their work they showed that putting an activator level can be used as a useful bargaining tool in the preconstruction phase for measuring contractor default using only timely stock information.

5. The sentence is now divided into two sentences.

6. The authors checked the manuscript for such issues therefore the following corrections are now made:

In the abstract section, paragraph 1, "land-shortage" is now replaced with "land shortage"

In the introduction section, paragraph 2, "Postdisaster" is now replaced with "post-disaster"

In the introduction section, paragraph 3 , an unnecessary comma after the word "activities" is now removed. 
Check for correct numbering of tables. The author(s) have inserted a figure 1 (which is very clear), however, on page 12, line 60, it should be Figure 3 (not figure 2). Please check if all the figures and tables match as per the referencing in the paper.
In the section 5.2.3, "built area" is replaced with "built areas"

7. Authors checked the manuscript for tables and figures numbering errors and to ensure all the figures and tables match as per the referencing in the paper. Corrections are made where necessary and changes are highlighted throughout the text. 
Real options analysis of revenue risk sharing in post-disaster housing reconstruction

\author{
Vahdatmanesh, $\mathrm{M}$
}

2021

22/04/2023 - Downloaded from MASSEY RESEARCH ONLINE 